\title{
Quebec strikes committee on Clostridium difficile
}

The Quebec government has struck an expert committee to assess the extent of a Clostridium difficile outbreak affecting hospitals in the province and to recommend infection control strategies.

The committee, announced June 10 , is an offshoot of the Committee on Nosocomial Infections in Quebec. It will report through the Ministry of Public Health to Health Minister Philippe Couillard.

The committee of microbiologists, infection control officers, public health officials and infectious disease specialists has already issued recommendations advising hospitals to strengthen their infection control procedures, says Dr. Charles Frenette, the chair. He did not provide a date for a final report.

To facilitate increased surveillance and reporting of $C$. dif$\approx$ ficile, the National Institute of Public Health of Quebec (INSPQ) will set up a specific computer monitoring database.

When surveillance data are available, the committee will forward them to public health and the ministry, says Frenette.
He anticipates the government will release that data.

"I would expect that there will be pressure to make it public," he says.

Quebec hospitals will now have to track and report cases of C. difficile, says Dr. John Carsley of the Montreal public health department.

The additional surveillance and expert committee follow a CMAf investigation, as reported online June 4 and in the July 6 issue (CMA7 2004;172[1]:1921 , into an outbreak of $C$. difficile diarrhea in at least 12 hospitals in Montréal over the past 18 months. Hospitals in Calgary are also seeing increased cases of the infection. CMA7 elicited reports of at least 83 deaths in the 2 cities - the vast majority in Montréal — in 2003 and the first quarter of 2004.

Also in response to the news reports, the McGill University Health Centre set up a hotline at its 5 member hospitals. In the first 2 days, nurses staffing the phones received 150 calls from concerned patients. About half wondered if they should post- pone tests or elective surgery at the MUHC for fear of contracting the infection; the other half were calls from patients at other Montréal hospitals looking for information about $C$. difficile, its symptoms and treatment, says Christine Zeindler, communications coordinator for the MUHC.

Nurses told patients they should keep their appointments for all tests, but should discuss elective surgeries and potential risks of contracting $C$. difficile with their physicians, Zeindler says.

The MUHC saw 780 patients with $C$. difficile in the fiscal year

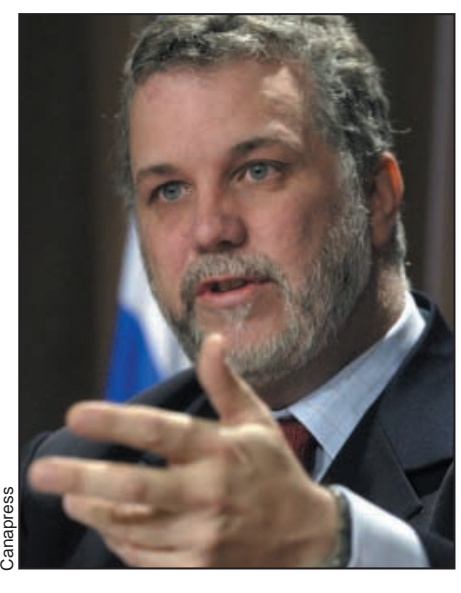

Quebec Health Minister Philippe Couillard: waiting for the results.
2003/04, 84\% of whom contracted the infection in hospital, according to an advisory they issued the day CMAZ released its story online. Of those patients, 36 died from $C$. difficile related complications and another 12 required colorectal surgery, according to the institution. - Laura Eggertson, CMAJ

\section{Patient Safety}

\section{Medical error affects nearly $25 \%$ of Canadians}

Medical errors in Canada are common, and there are significant regional disparities in how the health care system performs, according to a June 9 report by the Canadian Institute for Health Information (CIHI).

Health Care in Canada 2004, CIHI's annual report on the health care system, found almost 1 of every 4 Canadians (5.2 mil$\hat{o}$ lion people) say they or a family member has experienced a preventable, adverse event in 2003.

The adverse events range from receiving the wrong dose or type of medication, to having foreign objects left in the body after surgery. One in 9 adults with health problems said a health professional or hospital gave them the wrong medication or dosage, while 1 in every 6667 surgical patients had a foreign object left in their body. The errors are associated with $1.1 \mathrm{mil}-$ lion extra days in hospital.

"Some errors can be avoided through simple solutions, such as marking a knee with a pen to ensure the correct knee is operated on," said Dr. Indra Pulcins, manager of health indicators at CIHI. "Other possible solutions, such as implementing electronic prescribing to avoid medication errors, are more complex."

There were substantial differ- ences across Canada in some health performance indicators. In Nova Scotia, for example, $24.2 \%$ of patients who suffered a stroke died in hospital within 30 days, while in Alberta, the rate was $15.5 \%$.

It's difficult to say why provinces perform differently, says Pulcins. "It may be related to the quality of care in hospital, or the medication that was prescribed, or whether or not the appropriate diagnostic workup was done. The statistic acts as a flag to the health region. If there is a high mortality rate, they can try to identify how to address it." - Louise Gagnon, Ottawa 